\title{
A teOria da REMINISCÊnCIA EM AgOSTINHO: APROPRIAÇão E CRÍTICA
}

\author{
[THE THEORY OF REMINISCENCE IN AUGUSTINE: APPROPRIATION AND CRITICISM]
}

\author{
Daniel Rodrigues da Costa * \\ Universidade Federal de Minas Gerais, Brasil
}

RESUMO: Este artigo tem por objeto a recepção da teoria platônica da reminiscência em Agostinho e visa apresentar como o bispo de Hipona se apropria da tese de Platão para construir sua teoria da iluminação. Desde os textos fundamentais da teoria do conhecimento de Platão existe a discussão sobre a validade ou não da chamada reminiscência e qual seria seu verdadeiro conteúdo. Agostinho, séculos depois, se depara com o mesmo problema explorado por ele e necessita de uma resposta diferente: explicar conhecimentos presentes na alma não oriundos da experiência e, contudo, não oriundos da preexistência da alma. Iremos abordar, portanto, o movimento de recepção, crítica e apropriação de Agostinho para com a teoria platônica, bem como a resposta agostiniana para o problema a que Platão, segundo ele, não responde satisfatoriamente.

Palavras-ChaVe: Reminiscência; Iluminação; Verdade; Preexistência.
ABSTRACT: This article aims at receiving the Platonic theory of reminiscence in Augustine and aims to present how the bishop of Hippo appropriates Plato's thesis to build his theory of illumination. From the fundamental texts of Plato's theory of knowledge there is a discussion about the validity or otherwise of the so-called reminiscence and what would be its true content. Augustine, centuries later, is faced with the same problem explored by him and needs a different answer: to explain knowledge present in the soul that does not originate from experience and yet does not come from the preexistence of the soul. We shall therefore approach Augustine's movement of reception, criticism, and appropriation of Platonic theory, as well as the Augustinian answer to the problem to which Plato, according to him, does not respond satisfactorily.

KEYWORDS: Reminiscence; illumination; Truth; Preexistence

\section{INTRODUÇÃO: O PLATONISMO COMO UMA NOVA PERSPECTIVA INTELECTUAL}

Supõe que tenhas esquecido alguma coisa e que outros queiram que te recordes daquilo. Então eles, mencionando coisas diversas como se fossem semelhantes, te perguntam: é isso ou aquilo? Mas nem sequer lhe vem à mente aquilo que desejas recordar e, contudo, vês que não é o que eles mencionam. Quando isto acontece, achas que é um esquecimento total? Já o próprio discernimento, pelo qual não admites ser erroneamente convencido, de certo modo é parte da recordação. [...] Aqueles com os quais isto acontece ainda não vêem a verdade, mas não podem ser enganados nem induzidos a erro e sabem suficientemente o que buscam. ${ }^{1}$

* Doutorando em Filosofia pela Universidade de São Paulo. Mestre em Filosofia pela Universidade Federal de Minas Gerais - UFMG. E-mail: dan.costaecosta@gmail.com 
$\square$ ssa poderia ser uma citação que mencionasse o processo de anamnese, de esquecimento e recordação em algum texto de Platão, e mesmo um estudioso teria dificuldade de desmentir essa afirmativa. Entretanto, a passagem é um excerto do texto Soliloquios, de Agostinho, escrito pelo menos seis séculos depois de Platão. É sabido que o bispo de Hipona segue na esteira dos platônicos em muitos de

152 seus aspectos, e a teoria do conhecimento, talvez, seja o principal deles. Entretanto, existem diferenças fundamentais que marcam as duas teorias: embora ambas busquem responder à questão da presença da verdade na alma e das condições para o seu conhecimento, ou melhor, reconhecimento, Agostinho não aceitaria a resposta platônica por, segundo ele, confundir a memória do passado com a memória do presente.

O primeiro contato de Agostinho com os textos platônicos é relatado por ele nas Confissões, onde afirma ter recebido, por mãos de um certo homem, "inchado por enorme orgulho, alguns livros platônicos, traduzidos do grego para o latim"2. Esse contato com o platonismo ${ }^{3}$ é responsável por lhe proporcionar uma nova perspectiva intelectual e espiritual: o grande problema que incomodava Agostinho naquele período era a impossibilidade de conceber uma substância imaterial. Ambrósio, com seu platonismo cristianizado, ofereceu a Agostinho uma nova perspectiva e garantiu que o jovem pudesse superar o materialismo maniqueu ${ }^{4}$. Tempos depois, em contato mais estreito com a teoria do conhecimento e às voltas com o problema das condições de possibilidade para o conhecimento da verdade, Agostinho encontraria suporte na anamnese. Sua dificuldade estava em justificar o acesso ao conhecimento seguro e, uma vez que as demais possibilidades estavam vedadas, a tese platônica se apresentava como um bom argumento.

A teoria do conhecimento de Agostinho é dividida em três fases, cada qual apontando para a fase seguinte até que chegue à doutrina da iluminação ${ }^{5}$. No conhecimento sensível, Agostinho explora a ideia, comum também aos platônicos, de que todo conhecimento que tem os dados sensíveis como alvo possui um conteúdo inteligível, destacando o papel ativo da alma. A função da alma, que é conferir vida ao corpo a que está unida, só será desempenhado em sua plenitude se ela, ao fazer o corpo ter vida, também lhe conferir a unidade de suas partes e estiver atenta a qualquer ação nociva externa que lhe possa ameaçar. Portanto, de acordo com o que é a definiç̧ão de sensação ${ }^{6}$, quando um sensível entra em contato com o corpo, é função da alma atentar a tal modificação a fim de preservar todas as funções do corpo que ela anima, apreendendo tais modificações de acordo com sua natureza. Sensação só existe quando há envolvido um corpo vivificado por uma alma, pois somente a alma sente. Essa teoria, além de resolver o problema quanto à impossibilidade do inferior ser causa de algo no superior ${ }^{7}$, também aponta para a interioridade do conhecimento, ou seja, explicita que o conhecimento que aparentemente se originaria no dado sensível se origina, na verdade, de um movimento ativo da alma que tem o corpo apenas como meio ${ }^{8}$.

No conhecimento inteligível, Agostinho utiliza o exemplo do ensino para provar que nenhuma de nossas ideias nos vem "de fora", ou seja, não são adquiridas pelo processo de aprendizagem. Tanto nos casos em que o mestre queira ensinar o discípulo algo referente à natureza sensível ${ }^{9}$, quanto nos casos em que queira ensinar sobre o sentido de uma coisa não há, segundo Agostinho, uma transmissão de ideias. Como não há um paralelismo rigoroso entre linguagem e pensamento ${ }^{10}$, as ideias não nos vêm contidas na linguagem: tudo o que uma conversa ou uma aula podem fazer é despertar no interlocutor ou no discípulo ideias que ele próprio já possui. Quando meu interlocutor me descreve uma cidade que não conheço, o que minha alma faz é preencher a imagem de cidade que tenho em minha memória com as descrições que me são dadas. De modo parecido, quando meu interlocutor me fala sobre seus sentimentos naquele momento, o que minha alma faz é recordar momentos em que meus sentimentos foram descritivamente semelhantes com aqueles que meu interlocutor 
informa, transportando através de um conceito um estado da minha alma e projetando-o no meu interlocutor. Se o mestre ou o interlocutor descreve o modo como compreendeu determinada passagem de um livro, o que a alma faz é atentar ao que está sendo dito e julgar, por si própria, se aquilo é verdadeiro ou não; se a alma desconhece o assunto que está sendo descrito e não tem capacidade de decidir se aquela descrição é verdadeira (válida) ou não, ela optará ou pela autoridade ou por debruçar-se sobre a passagem e retirar de si a capacidade de julgar tal interpretação. Os exemplos se multiplicam e todos, segundo Agostinho, nos mostram a mesma conclusão: a linguagem, através da qual nos advém a comunicação e o ensino, não nos transmite nenhuma nova ideia, tudo o que ela faz é revelar as ideias que já estão em nós ${ }^{11}$.

Essa tese de que não adquirimos nenhum conhecimento "de fora", mas que todo o processo de aprendizagem se resume a descobrir em si as ideias verdadeiras que chamamos conhecimento ou ciência, através do questionamento, possui, sem dúvida, suas raízes em Platão. Desde o Menon e sua teoria da reminiscência, em que Sócrates, ao realizar o experimento com o escravo, estaria demonstrando como a alma humana possui ideias independentemente de sua educação neste mundo, e que para descobri-las bastaria o correto questionamento para o correto direcionamento da alma, Agostinho viu desenvolvida a base para a sua teoria do conhecimento. Ao analisar, no Sobre o Mestre, a relação entre linguagem e pensamento, é à teoria platônica da reminiscência que ele, por um lado, se mostra devedor, e, por outro, que ele precisa aperfeiçoar.

\section{O DUPLO MOVIMENTO DE APROPRIAÇÃO DA REMINISCÊNCIA}

O que há de verdade permanente na doutrina do Menon é que o pensamento encontra o inteligível em vez de criá-lo; o erro de Platão foi imaginar não se sabe qual preexistência da alma em relação ao corpo para atribuir razão a esse fato. $\mathrm{Na}$ verdade, Platão tem razão em dizer que a alma encontra a verdade em si mesma; conclui mal, a partir disso, que ela se lembra da verdade como nos lembramos de um conhecimento passado. ${ }^{12}$

Essa atitude para com a teoria da reminiscência, que Gilson nos apresenta, é uma expressão da maturidade de Agostinho. Para responder à questão da presença de conhecimentos na alma independentes da experiência, Agostinho irá se apoiar na reminiscência platônica. Entretanto, a reminiscência que Platão nos apresenta no Menon incluiria a tese da preexistência da alma, ou seja, que para explicar a existência de determinados conhecimentos na alma, é necessário que ela tenha existido antes de sua união com este corpo, onde contemplou todas as verdades ${ }^{13}$. De modo semelhante, no Fedon, Platão defende que a alma sobrevive em separado do corpo, uma vez que, observados certos conhecimentos que ela não adquiriu nesta vida, ela só pode tê-los adquirido em outra vida, quando não era este homem. A reminiscência, portanto, comporta necessariamente a preexistência da alma, uma vez que qualquer explicação que a tese cobre ficaria ela mesma ininteligível caso a alma não preexistisse ao corpo e tivesse, naquele período, contemplado as verdades que agora rememora ${ }^{14}$.

O mesmo problema que ocupara Platão ocupa agora Agostinho: se a alma não adquire suas ideias a partir do contato com o corpo, nem as adquire a partir do ensino, por meio da linguagem, de onde nos viriam essas ideias ${ }^{15}$ ? A tese que Agostinho analisa aponta para o recebimento dessas ideias de algum outro lugar ${ }^{16}$, e nos textos de Cassicíaco, escritos logo após a conversão e nos quais Agostinho está sob o influxo dos platonicorum libros $^{17}$, não é irrazoável que ele as imaginasse vindo de algo como a reminiscência. Platão propõe uma espécie de inatismo ${ }^{18}$ que é bem abarcado pela experiência do Menon e responde bem, por sua vez, ao questionamento inicial do diálogo e ao aparentemente insolúvel problema da circularidade do conhecimento 
(Menon 80d). Já Agostinho, embora ainda não precisasse lidar diretamente com o problema da circularidade do conhecimento ${ }^{19}$, buscava em Platão a solução para o problema da origem das ideias. Beierwalte ${ }^{20}$ confirma que o jovem Agostinho, naquele período, concede à teoria da reminiscência (recordatio) um lugar de destaque ante as outras possibilidades, mesmo que não fosse capaz de decidir-se por ela como exata

154 expressão de seu pensamento. Já Gilson ${ }^{21}$ nos mostra o quão difícil é rastrear a exata posição de Agostinho, pois os anos de 387 a 389 abarcam exatamente o período de transformação do que ele teria recebido dos platônicos e do que, mais tarde, iria propor por si. Ainda assim, ao observar algumas de suas obras, tanto as escritas naquele período (Soliloq. II, 20; De quant. animae XX, 34), quanto as escritas mais tarde e que são mostra de sua filosofia "definitiva" (De Civ. Dei, X, 30; Retract., VIII, 2; 32), é possível interpretar esse período como sendo de um amadurecimento do que ele havia recebido da filosofia de Platão.

O período logo após a conversão, tanto em Cassicíaco quanto em Milão e no regresso à África, foi um período marcado pelo desatar das amarras que prendiam Agostinho ao serviço público. Foi também um período de ócio (otium) filosófico e Agostinho pôde dedicar-se a problemas que surgiam de suas meditações. No Sobre a quant. da alma, escrito logo após seu batismo em Milão, Agostinho empreende responder alguns questionamentos que seu amigo Evódio lhe havia feito sobre a alma humana, em especial sobre sua magnitude ${ }^{22}$. Evódio questionava as propriedades da alma, pois, ao não possuir dimensões como as corpóreas, lhe parecia que a alma era nada, algo absolutamente intangível, e algo assim lhe parecia destituído de existência. Essa mesma posição tivera Agostinho, quando adepto do Maniqueísmo, pois era incapaz de conceber uma substância que não possuísse dimensões corpóreas. Para responder a Evódio, Agostinho afirma que a alma deve ser incorpórea, pois deve ser "[...] certa substância que é partícipe da razão adequada para governar o corpo"23. Mas, é no questionamento de Evódio sobre se, dada a união da alma com o corpo, aquela não teria trazido consigo alguma arte ao homem, Agostinho afirma que, segundo sua opinião, a alma teria trazido todas as artes consigo, e que aquilo que nós chamamos de conhecimento é, na verdade, a recordação dessas artes ${ }^{24}$. Essa resposta joga Agostinho diretamente na teoria da reminiscência do Menon, pois, como afirma Sócrates após o escravo ter dado respostas verdadeiras sobre a Geometria sem que aquele conhecimento lhe tivesse sido ensinado, que "deve haver nele opiniões verdadeiras que, sendo despertadas pelo questionamento, se tornam ciências" (Menon 86a). Assim, da mesma forma que a resposta de Platão para a presença de conhecimentos verdadeiros na alma do escravo é a reminiscência, para Agostinho, a resposta para as artes, e todas as artes, que o homem demonstra nessa vida é também a recordação. Excetuados os casos de conhecimentos oriundos da experiência, em todos os outros casos Agostinho afirma, no referido texto, que a alma traz consigo os conhecimentos que demonstra aqui.

Embora Agostinho não desenvolva o que ele entende por recordação e reminiscência das artes que a alma traz consigo, e que nem mesmo o Sobre a quant. da alma seja um diálogo conclusivo sobre a origem da alma e sua anterioridade em relação ao corpo, é patente que Agostinho demonstra uma posição muito próxima do que ele entendia como a reminiscência platônica nesse período. Gilson ${ }^{25}$ chega a nos dizer que, nos textos daquela época, Agostinho usa os termos "esquecimento" e "reminiscência" como se eles conservassem o sentido preciso que possuem na filosofia platônica. Outro exemplo disso está nos Soliloquios, texto também escrito no período pós-conversão, onde Agostinho dialoga com sua razão, ou melhor, com a razão, a fim de compreender sua alma e Deus ${ }^{26}$. Nesse diálogo, além de diversas indicações do que viria a se consolidar posteriormente como sua teoria do conhecimento (I, IV, 9; I, IV, 12; I, VIII, 15; II, I, 1; II, III, 3; II, IV, 6), e algumas analogias muito próximas das analogias propostas por Platão (I, XIII, 23), Agostinho aponta para uma conclusão que ele mesmo não faz, mas cuja ilação está implícita. Nos dois últimos capítulos do livro II, a razão, 
buscando provar a imortalidade da alma humana, afirma que a verdade está presente na alma e que ela não pode perecer, uma vez que sempre haverá algo de verdadeiro. Dado que, ou a verdade não perece e isto é verdadeiro, ou a verdade perece e isto é verdadeiro, mas, então, nada de verdadeiro pode existir se a verdade perece, pois o que é verdadeiro deriva sua existência da verdade; logo, como sempre será verdadeiro ou que a verdade perece ou que ela não perece, e, portanto, sempre haverá algo de verdadeiro, sempre existirá a verdade. Se a verdade está sempre presente na alma, segue-se que a alma não pode perecer, pois se perecesse, a verdade pereceria, o que foi demonstrado ser impossível27.

Dada essa conclusão, Agostinho diz aceitá-la, mas pergunta à razão como compreender que a verdade e a ciência estejam na alma do ignorante, já que ele, aparentemente, desconhece a verdade, mas não se pode dizer que sua alma seja mortal $^{28}$. A razão diz ser esta uma grande questão e que não a trataria naquela ocasião; entretanto, o último capítulo traz ainda um vislumbre do que Agostinho provavelmente considerasse como a resposta possível para essa questão. Ao tratar da diferença entre a verdade apreendida pela inteligência e a fantasia oriunda da imaginação, a razão afirma que a verdade está na alma e é, de certa forma, recordada quando investigada, pois o homem, ainda que desconheça aquilo que busca, sabe ao menos distinguir o que busca daquilo que não é o que busca ${ }^{29}$.

Assim, a alma busca a verdade ainda que não saiba o que seja a verdade, pois possui dela uma espécie de lembrança que a faz saber, ao menos, distinguir entre aquilo que busca. Agostinho confirma ser de fato assim que ocorre com nossa memória e nossa inteligência. Entretanto, a razão faz uma analogia com o conhecimento das artes liberais que, no mínimo, confirma uma proximidade filosófica muito estreita com a reminiscência platônica, afirmando que o conhecimento dessas artes é como que escavado na memória, pois estão soterrados pelo esquecimento ${ }^{30}$. Se a razão está afirmando que o conhecimento das artes liberais, uma vez tendo sido aprendidos nesta vida, são esquecidos e, então, recordados quando necessários por aquele que os detém, se trata de um simples processo de recordação; entretanto, toda a argumentação anterior, que dizia respeito ao conhecimento da verdade e como esse conhecimento está na alma, inclusive dos ignorantes, nos leva a estabelecer uma ligação com a reminiscência, uma espécie de conhecimento da verdade que independe das experiências desta vida. Isso porque a analogia diz respeito ao conhecimento da verdade, cujo "esplendor já se projeta nessas artes", e a ação da memória ao revolvê-las é uma ação em busca do conhecimento da verdade.

Apesar de toda a dificuldade em saber até que ponto Agostinho aceitava a tese platônica da reminiscência e de que maneira ele a interpretava ${ }^{31}$, os textos selecionados aqui nos dão mostra do quão próxima sua filosofia estava daquela de Platão no período destacado. E um fato em especial corrobora a nossa ideia de que, durante seu percurso, Agostinho amadurece aquilo que recebe dos platônicos e que isto pudesse significar, enfim, que ele aceitava a reminiscência no período pós-conversão e que, em sua maturidade, ele passasse a demarcar suas diferenças para com ela: a retificação de algumas passagens em sua obra que demarcam essa diferença, em especial nas Retratações, e que, por sua vez, nos leva ao que seria a filosofia definitiva de Agostinho.

As Retratações são um texto que Agostinho escreve em 426/7 com o objetivo de, ao revisitar sua produção, corrigir alguns pontos que tivesse dado adesão equivocadamente quando os escrevia, em uma espécie de revisão crítica de seus escritos. Assim como as Confissões são uma avaliação crítica de seu percurso biográfico, as Retratações são uma avaliação crítica de sua produção filosófica e teológica. Aqui, nos interessa exatamente o ponto que acabamos de abordar, ou seja, a implícita menção à reminiscência nos capítulos finais dos Soliloquios e a, embora não literal, explícita menção à reminiscência platônica no Sobre a quant. da alma. Na parte 
referente aos Soliloquios nas Retratações, além de afirmar que o texto é inacabado, Agostinho demarca exatamente suas diferenças para com a reminiscência de Platão: havendo dito, então, que as pessoas descobrem em si mesmas os conteúdos uma vez apreendidos, mas esquecidos, e que, portanto, aprender é recordar, Agostinho escreve, agora, que é mais certo que os ignorantes respondam coisas verdadeiras porque tem

156 presentes em si a luz da razão eterna, e não porque alguma vez tenham conhecido as verdades imutáveis, como acreditava Platão ${ }^{32}$. Ou seja, se para Platão o "inatismo" das verdades na alma implicava a preexistência da alma, para Agostinho, esse "inatismo"33 não necessariamente a implica, pois o homem não conhece a verdade por tê-la apreendida "antes" 34 , mas por apreendê-la agora, através da luz que cada alma racional possui.

Para corroborar sua nova posição, Agostinho indica o livro XII do Sobre a Trindade, onde ele empreende, dentre outras coisas, realizar uma distinção entre a razão inferior, função da alma destinada a governar os sentidos e seu contato com o exterior e o sensível, e a razão superior, função da alma destinada à intelecção das verdades inteligíveis, dentre elas, o conhecimento da alma e de Deus ${ }^{35}$. Já no capítulo II do referido livro, Agostinho afirma que a razão superior é capaz de julgar as realidades corporais segundo razões incorpóreas e eternas. Essas razões eternas estão acima mesmo da mente humana, mas nossa mente possui para com elas certa ligação que lhe permite realizar tais juízos. Mas é a partir do capítulo XIV que Agostinho apresenta algumas marcas de sua teoria do conhecimento, como quando diz que o pensamento acessa o conhecimento das razões inteligíveis na verdade incorpórea (incorporea veritate), e grava-as na memória a fim de instruir o espírito a retornar a elas, já que sua contemplação é rápida e fugaz. No capítulo XV, finalmente, Agostinho explica e critica a teoria da reminiscência de Platão, pois este teria pensado, uma vez detectado que o acesso a tais razões inteligíveis se dá através da memória, que a alma teria vivido antes dessa vida e contemplado, então, as razões. A crítica de Agostinho interpreta a reminiscência como o conhecimento de uma vida anterior, em que o homem aprendeu certas ciências e as rememora aqui, nesta vida. Daí Agostinho afirmar que, sendo interrogado sobre determinada ciência nesta vida, poucos saberiam responder coisas verdadeiras, pois poucos teriam sido, por exemplo, geômetras na vida anterior. Caberia uma crítica à interpretação de Agostinho, pois ela deixa de lado diversos elementos que completam a reminiscência e atém-se apenas ao aspecto transmigracional da alma. Mas aqui interessa-nos mais comparar essas afirmações com o que está escrito nos Soliloquios e em suas retratações, pois abarcam aquilo que delimitamos no início, de que Agostinho, em sua filosofia definitiva, demarca suas diferenças para com a sua compreensão inicial da teoria platônica.

Realizada a crítica à reminiscência e à preexistência da alma, Agostinho afirma, conforme aponta nas Retratações, que é mais sensato acreditar que a alma foi criada de tal maneira que, ao se dedicar ao inteligível segundo sua natureza, é capaz de ver essas razões eternas por intermédio de certa luz incorpórea que faz parte de sua natureza. Por conseguinte, o homem se lembra nessa vida das verdades inteligíveis porque, por sua natureza, pode contemplar essas verdades através de sua alma intelectiva, que as contempla através de uma luz incorpórea; analogamente, o olho contempla os objetos sensíveis através de certa luz corpórea, pois sua natureza foi feita conforme essa luz corpórea, o que lhe propicia tal contemplação. Assim, a teoria do conhecimento das verdades eternas que Agostinho propõe já está descolada da proposta por Platão, à qual ele parecia se inclinar ou mesmo dar adesão no período pós-conversão.

\section{A REMINISCÊNCIA DE MOdo DEFINITIVo EM Agostinho}

Se, portanto, em um primeiro momento, Agostinho parece dar adesão ao que a 
reminiscência platônica lhe oferecia, conforme os textos Sobre a quant. da alma e Soliloquios, contudo, nos textos mais maduros, como A Cidade de Deus e as Retratações, ele apresenta sua crítica à tese platônica e oferece, por sua vez, sua própria solução para o problema da origem e do acesso da alma ao conhecimento seguro, a teoria da iluminação. Essa teoria afirma que a alma possui uma espécie de mestre interior (De magistro), um guia da razão natural, que a direciona corretamente na busca pela verdade. Essa busca, entretanto, não é externa à própria alma e não é contemplada em um momento qualquer esquecido depois. A verdade se encontra na alma mesma e é através da iluminação divina que pode ser descoberta presente em nós. Essa tese não defende, entretanto, o inatismo de todos os conhecimentos na alma, pois não se trata de, uma vez corretamente direcionado, o homem poder descobrir em sua alma o conhecimento de todas as coisas. Agostinho rechaçaria veementemente a ideia de que, uma vez tendo contemplado todas as verdades numa vida anterior, o homem pudesse manifestar nessa vida o conhecimento contemplado ${ }^{36}$. Essa é, também, uma das principais críticas de Agostinho à reminiscência de Platão, pois, se a alma tivesse contemplado todas as coisas antes do nascimento, ela deveria possuir em potencial o conhecimento de todas as coisas, inclusive das coisas sensíveis, como qual o gosto do mel ou o melhor caminho de Hipona a Tagaste. É evidente que a alma não conhece essas coisas antes de tê-las experimentado. A verdade das coisas que se encontra na alma, portanto, se refere apenas aos inteligíveis ${ }^{37}$.

Mas não é sem dificuldades que a reminiscência, com tudo o que ela comporta, é afastada do pensamento de Agostinho (se de fato é). Na parte referente às retificações do Sobre a quant. da alma nas Retratações, Agostinho, que havia dito antes que a alma trazia consigo todas as artes "antes" do nascimento, e que o que chamamos aprendizado é, na verdade, recordação, afirma agora que essa frase não deve ser entendida como se quisesse dizer que a alma tenha vivido alguma vez, neste ou em outro corpo, em um corpo ou fora de um. A crítica de Agostinho segue no sentido da afirmação seguinte, de que existem artes que pertencem aos sentidos corporais e que essas não poderiam advir à alma antes do nascimento deste homem. Assim, a experiência do Menon, em que a alma é interrogada sobre seus conhecimentos, só funcionaria com aqueles conhecimentos aos quais somente a inteligência abarca, em que não se necessita dos sentidos. Mas, como se percebe, a retificação que Agostinho faz não elimina a reminiscência platônica, nem sequer a possibilidade de preexistência da alma. Conforme foi mostrado acima, no livro XII do Sobre a Trindade, Agostinho rechaça a possibilidade de transmigração das almas, mas, como ele próprio nunca chegou a solucionar o problema da origem das $\operatorname{almas}^{38}$, não podemos afirmar que Agostinho elimine qualquer possibilidade de sua preexistência em relação ao corpo. Nessa mesma parte das Retratações, após afirmar que sua frase não devia ser entendida como se estivesse afirmando a existência prévia da alma, e antes de afirmar a sua teoria (de que a alma pode acessar as verdades inteligíveis porque sua natureza foi criada assim), ele coloca a ambiguidade que não nos permite afirmar a eliminação da preexistência da alma; ele diz: "Fieri enim potest [...] ut hoc ideo possit..." 39 .

Tendo dito anteriormente qual não era a forma em que sua frase deveria ser entendida, ele coloca em seguida uma adversativa fraca, deixando dúvida quanto à sua real posição, ao dizer algo do tipo: "na verdade, pode suceder que isto seja possível", ou seja, pode ser possível que a alma tenha existido antes, pois ela é capaz de entender as coisas inteligíveis e imutáveis. Como fica exposto, Agostinho não rechaça a possibilidade de preexistência da alma, o que leva Gilson a dizer que "é possível acreditar com muita verossimilhança que ele jamais rejeitará como certamente falsa a ideia de uma possível preexistência da alma em relação ao corpo"40. Mas, ainda assim, como foi dito nas retratações dos Soliloquios, é mais correto dizer que ela compreende as coisas inteligíveis e imutáveis através de uma luz que lhe é presente. O problema da origem das almas não é totalmente solucionado por Agostinho, o que o impede de 
eliminar a possibilidade da preexistência dela. O que podemos afirmar, sem dúvida, é que a teoria do conhecimento metafísico de Agostinho, a chamada iluminação, não necessita da preexistência da alma como a reminiscência platônica necessita (ou parece necessitar, segundo essa interpretação inicial de Agostinho). E essa não necessidade da preexistência torna possível transformar a lembrança do passado que a reminiscência

158 platônica traz em uma lembrança do presente, marca da doutrina da iluminação de Agostinho.

Quando a alma não pode ser induzida a erro, como explicitado na passagem dos Soliloquios $^{41}$, é porque, embora ela não se lembre com exatidão o que procura, ela não esqueceu completamente o seu objeto de desejo. É isso que ocorre no esquecimento parcial de algo, e é também o que ocorre, segundo Agostinho, com as verdades impressas em nossa memória. Embora elas não estejam presentes ao pensamento, depositadas na memória desde a criação da alma, essas verdades precisam ser iluminadas pela luz divina para que o intelecto possa observá-las. Mas, mesmo quando o intelecto não as observa, não há um esquecimento total dessas verdades, porque elas são como a marca do anel na cera: o anel pode não estar mais presente, mas a marca na cera é prova de que ele, alguma vez, esteve ${ }^{42}$. As verdades impressas na memória de todos os homens provam, por sua vez, que todos os homens podem conhecer a verdade se sua razão natural os direcionar corretamente e se a iluminação divina lhes propiciar tal conhecimento. Esse conhecimento, contudo, não é a lembrança do passado, do "momento" da contemplação ou do aprendizado das verdades, mas a atividade da memória no presente, que descobre em si tais conteúdos.

A tese de Agostinho é que toda alma possui em si algo transcendente, a partir do qual pode julgar a adequação das coisas ordinárias à verdade, não porque alguma vez contemplou a verdade, mas porque a própria verdade foi impressa na alma quando de sua criação ${ }^{43}$. Quando Platão, portanto, oferece a preexistência da alma para explicar a presença de conhecimentos não oriundos da experiência e para justificar o acesso ao conhecimento seguro, ele se apóia na ideia de que tal preexistência justificaria uma lembrança do passado ${ }^{4}$. O que Agostinho percebe, por sua vez, é que o acesso a tais conteúdos é uma função da memória do presente, que recebe, através da iluminação, o conhecimento da verdade. Não obstante tal crítica e a necessidade que o bispo de Hipona demonstra de se afastar da tese platônica, é sem dúvida que ela fornece grande parte do combustível que Agostinho precisava para construir sua teoria e que, seja de modo explícito ou implícito, ele é devedor do que recebe de Platão.

\section{REFERÊNCIAS}

Citamos os textos de Agostinho, em língua latina, segundo a edição coletiva $S$. Aurelii Augustini Opera Omnia: editio latina, organizada por Città Nuova Editrice e Nuova Biblioteca Agostiniana, e disponível em www.augustinus.it. Em relação às passagens citadas das Confissões e do Sobre a Trindade, a tradução é de nossa responsabilidade. Das demais obras, as referências são as seguintes:

AURELIUS AUGUSTINUS. Les Révisions. Traduzido do latim por Gustave Bardy. Paris: Desclée de Brouwer, 1950. 663 p. (Bibliothèque Augustinienne, 12).

AURELIUS AUGUSTINUS. Sobre a potencialidade da alma - De quantitade animae. Tradução de Aloysio Jansen de Faria. Petrópolis: Vozes, 1997.

AURELIUS AUGUSTINUS. Sobre o Mestre. Tradução de Angelo Ricci. São Paulo: Abril, 1973 (col.“Os Pensadores”, VI).

AURELIUS AUGUSTINUS. Solilóquios. Tradução de Ir. Nair de Assis Oliveira. São Paulo: Paulinas, 1993.

PLATÃO. Tutti gli Scritti. Università Cattolica del Sacro Cuore di Milano: Rusconi, 1997, sesta 
edizione. A cura di Giovanni Reale.

ALFARIC, P. L'évolution intellectuelle de saint Augustin, l. Du manichéisme au néoplatonisme. Paris: E. Nourry. 1918.

ALTMAN, W.H.F. The Revival of Platonism in Cicero's Late Philosophy. Platonis aemulus and the Invention of Cicero. p. xxxii +350 . Lanham, Boulder, New York and London: Lexington Books, 2016.

BEIERWALTES, W. Agostino e il neoplatonismo cristiano. [s.1]: Vita e Pensero, 1995.

BROWN, P. Santo Agostinho, uma biografia. [tradução Vera Ribeiro] - Rio de Janeiro: Record, 2005.

CAPANAGA, V. Augustin de Hipona, maestro de la conversión cristiana. Biblioteca

de autores cristianos. Madrid, 1974.

CAYRÉ, F. Initiation a la philosophie de saint Augustin. Paris, Études Augustiniennes, 1947.

CILlERUELO, L. "Por qué MemoriaDei?" In: Révue de études augustiniennes 9, 1963, p.289294.

CORNFORD, F. La teoria platônica del conocimiento - el Teeteto y el Sofista. Buenos Aires: Paidós, 1968.

DIXSAUT, M. Platão e a questão da alma. [tradução Cristina de Souza Agostini]. - São Paulo: Paulus, 2017.

GILSON, E. Introdução ao estudo de Santo Agostinho. Tradução Cristiane Negreiros Ayoub. Discurso Editorial; São Paulo: Paulus, 2006.

HESSEN, Joannes. Teoria do conhecimento. Tradução de João Vergílio Gallerani Cuter. Revisão técnica de Sérgio Sérvulo da Cunha. São Paulo: Martins Fontes, 1999.

MARROU, H. I. Saint Augustin et l'augustinisme, [s.l.] Maîtres spirituels, 1995.

SCOTT, D. Platonic anamnesis revisited. In: The Classical Quarterly 37 (ii) 346-366 (1987).

STREFLING, S. R. Os sete graus de atividade da alma humana no De quantitate animae de santo Agostinho.Trans/Form/Ação, Marília, v.37, n.3, p.179-200, Set./Dez., 2014.

\section{Notas}

1 Soliloq. II, XX, 34: "Fac enim te aliquid esse oblitum, aliosque te velle quasi in memoriam revocare Dicunt ergo illi: Numquidnam hoc est, aut illud? diversa velut similia proferentes. Tu vero nec illud vides quod recordari cupis; et tamen: vides non hoc esse quod dicitur. Numquidnam tibi cum hoc evenit, omni modo videtur oblivio? Nam ipsa discretio, qua non admittitur quod falso admoneris, pars quaedam recordationis est. [...]Tales ergo nondum verum vident; falli tamen decipique non possunt; et quid quaerant, satis norunt.".

2 Conf. VII, IX. Não é certeza ser este o primeiro contato de Agostinho com o platonismo. Durante sua formação, ele teria lido autores como Jâmblico e Apuleio. Além disso, conforme a tese de Altman (2016), o próprio Cícero seria platônico e responsável por trazer a Agostinho o interesse por essa corrente. Mas BROWN, 2005, p.100-101, salienta que este é o primeiro contato com a filosofia antimaterialista dos platônicos.

3 O termo usado por Agostinho nas Conf. VII, 9, é "platonici", de modo que usaremos a mesma denominação. Sabemos, entretanto, que os autores que se consideravam simplesmente "platônicos" possuíram uma doutrina suficientemente distinta da de seu mestre, de modo que, quando necessário, utilizaremos uma denominação específica.

4 Conf. VII, I, 1-2.

5 Cf. CAPANAGA, 1974, p.23: “"Tal es una de las descripciones que hace el Santo del descubrimiento de la luz interior. En ella aparecen tres clases de luz: la luz sensible y ordinaria, in que vemos los cuerpos; la luz espiritual, o el ojo mismo del alma, que es la mente, que es también luz creada, y la luz superior e inmutable, que no debe confundirse con las anteriores. Estas luces aparecen en un orden jerárquico: la sensible, la intelectual, la iluminante superior, o "Dios-Verdad, em quien, de quien y en quien son verdaderas todas las cosas."

6 Sensação é toda paixão sofrida pelo corpo quando ela não é ignorada pela alma e não lhe 
escapa. Cf. De quant. animae, XXIII, 41.

$7 \mathrm{Ou}$ seja, o corpo não poderia ser causa das ideias na alma. O que ocorre, então, é que a alma utiliza o corpo para retirar de sua função as sensações, mas não é o corpo que causa a sensação na alma, muito menos as ideias de acordo com a verdade. Cf. GILSON, 2006, p.132; 134; 137: "Perguntamos como o corpo poderia agir sobre a alma, enquanto o que se passa, na realidade, é algo totalmente diferente. É a alma que age e vela permanentemente por cada um dos órgãos do corpo no qual ela está presente. [...]. [Isto] indica precisamente que a alma é uma força espiritual sempre vigilante e presente: para sentir, ela não tem que receber nada dos órgãos que vivifica, basta que as modificações sofridas por esses órgãos não escapem a ela e penetrem no campo de sua atenção. [...] Desde o grau mais baixo do conhecimento, portanto, é uma alma transcendente ao corpo que intervém". Ver também: Soliloq. II, III, 3; II, IV, 6.

8 Se quisermos compreender essa tese como abstracionismo para a formação de conceitos, devemos distingui-la do todo da teoria da iluminação, pois, segundo defendemos, a iluminação não traz conceitos à alma, mas regras de julgamento dos conceitos. Para isso, ver: GILSON, 2006, p.189; CAYRÉ, 1947, p.227-230, 235; HESSEN, 1999, p.97-101; MARROU, 1995, p.70-71.

9 De magistro $\mathrm{X}, 33$.

10 Sobre essa questão, além da argumentação do De magistro, ver: P. ALFARIC. L'evolution intellectuelle de saint Augustin, 1918, p. 494-499.

11 GILSON, 2006, p.143.

12GILSON, 2006, p.155

13 Menon 86a: "E não é verdade que esse tempo é quando ele não era um ser humano? [...] Se, então, tanto durante o tempo em que ele for quanto durante o tempo em que não for um ser humano, deve haver nele opiniões verdadeiras que, sendo despertadas pelo questionamento, se tornam ciências; não é por todo o sempre que sua alma será uma alma que já tinha aprendido? Pois é evidente que é por todo o tempo que ele existe ou não existe como ser humano.".

14 Cornford (CORNFORD, F., 1968, p.18-19.) afirma que, no Menon, já se anunciava a reminiscência como a "recordação que se produz nessa vida de realidades e verdades vistas e conhecidas pela alma antes de sua encarnação", ou seja, extraindo um conhecimento que estava na alma do escravo, mas que ele não recordava, Sócrates prova duas teses: aquela de que quando se aprende, na verdade, se recorda, e a de que a alma é, portanto, imortal. Cornford, inclusive, defende a tese de que o verdadeiro desejo de Platão é provar a imortalidade da alma, e que a reminiscência é um meio para isso, o único satisfatório, e que a preexistência aparece como uma necessidade para completar o argumento. Essa interpretação, entretanto, não é unânime: muitos autores, como Monique Dixsaut (2017) e Dominic Scott (1987), questionam o tipo de conhecimento que a reminiscência traz à alma e, através disso, questionam o sentido geral da teoria. Para Dixsaut, por exemplo, a reminiscência não prova nem necessita da preexistência da alma, pois o que ela atesta é a participação, tanto ontológica quanto epistemológica, da alma naquilo que ela rememora; a lembrança, portanto, característica da reminiscência, é uma lembrança não de conteúdo, mas de natureza (p.99-101). Já Scott mostra que o tipo de conhecimento trazido pela reminiscência não tem como objetivo explicar como certos conhecimentos estão presentes na mente, mas sim mostrar a passagem da doxa, do mundo sensível e instável, para a episteme, o mundo inteligível e permanente. A reminiscência é, para além de um arcabouço de conceitos, uma ferramenta que possibilitaria o acesso à ciência, via dialética, porque a alma encontra nela mesma o parâmetro para o julgamento da doxa. O que Platão faz, segundo Scott, é mostrar a reminiscência em ação, "amarrando" uma opinião a um 'cálculo causal', à sua fundamentação, convertendo-a em conhecimento, ou seja, como o homem pode transformar uma opinião, adquirida por quaisquer meios, em conhecimento (p.351). Essas duas interpretações, além de diversas outras, nos servem para mostrar que a reminiscência é uma teoria cuja interpretação é questionada desde Platão. Nosso objetivo, entretanto, não se resume à discussão sobre a reminiscência, mas volta-se sobre a sua apropriação por Agostinho. 
15 A "ideia" a que me refiro aqui não é o conceito (o que nos levaria à tese do abstracionismo), mas ao conhecimento que não possui qualquer relação com a sensibilidade, diríamos, o conhecimento das razões eternas. Cf. De div. Quaest. 83, q.46; De Trin. IX, VII, 12.

16 A tese de que a alma produziria por conta própria suas ideias é rechaçada porque nos levaria à impossibilidade de conversação, pois cada homem teria suas próprias ideias e seus parâmetros de julgamento do mundo, nos sendo impossível partilhar noções comuns, como a matemática. Cf. GILSON, 2006, p.152.

17 BROWN, 2005, p.148.

18 Inatismo no sentido de que a alma contemplou as verdades e nasce, neste homem, tendo em sua memória o conhecimento das verdades.

19 Pois a lembrança da felicidade é a justificativa para o início da busca pelo conhecimento.

201995, p.81.

21 2006, p.147-150.

22 De quant. animae III, 4-36. As questões de Evódio ainda incluíam: a origem da alma, sua qualidade, o motivo de sua união com o corpo, o resultado da união e o resultado da separação. (In: STREFLING, S. R. Os sete graus de atividade da alma humana no De quantitate animae de santo Agostinho. Trans/Form/Ação, Marília, v.37, n.3, p.179-200, Set./Dez., 2014, p.181-182.).

23 De quant. animae XIII, 22: "Nam mihi videtur esse substantia quaedam rationis particeps, regendo corpori accommodata.". Em texto desse mesmo período, o De lib. arb. (I, XII, 24), também após um questionamento de Evódio sobre a justiça na condenação de um homem que, ignorante do que seja a virtude, prefere as paixões, Agostinho responde: "Ita istuc dicis, quasi liquido compertum habeas nunquam nos fuisse sapientes: attendis enim tempus ex quo in hanc vitam nati sumus. Sed cum sapientia in animo sit, utrum ante consortium huius corporis alia quadam vita vixerit animus, et an aliquando sapienter vixerit, magna quaestio est, magnum secretum, et suo considerandum loco [...]".

24 Ibidem, XX, 34: "Evódio: Accipio ista et assentior, nec tamen nihil angor ex eo quod imperita omnium rerum et bruta est anima, quam in puero recens nato quantum licet inspicimus. Cur enim nullam artem secum attulit, si aeterna est? Agostinho: Magnam omnino, magnam, et qua nescio utrum quidquam maius sit, quaestionem moves, in qua tantum nostrae sibimet opiniones adversantur, ut tibi anima nullam, mihi contra omnes artes secum attulisse videatur; nec aliud quidquam esse id quod dicitur discere, quam reminisci et recordari.".

25 GILSON, 2006, p.147.

26 Soliloq. I, II, 7; II, VII, 14.

27 Ibidem II, XV, 28.

28 Ibidem II, XIX, 33: "Audio, resipisco, recolere incipio. Sed, quaeso, illa quae restant expedias, quomodo in animo imperito, non enim eum mortalem dicere possumus, disciplina et veritas esse intellegantur."

29 Relembramos a passagem que abre este artigo, Solil. II, XX, 34.

30 Segundo Dixsaut, Platão emprega o verbo "laborar", no sentido de cavar a terra novamente, para se referir à metáfora da anamnese. $(2017, \mathrm{p} .83)$.

$31 \mathrm{Ou}$ seja, como Agostinho teria recebido a teoria da reminiscência, se a compreendendo como a afirmação da existência prévia da alma ou como a afirmação da semelhança da alma com as verdades que ela rememora. Aparentemente, como demonstraremos em seguida, Agostinho parece ter dado adesão ao primeiro tipo de interpretação, embora sempre deixe a impressão de que exista uma filosofia mais profunda em Platão. A sua teoria do conhecimento, contudo, é uma crítica à ideia de preexistência da alma, mas também não se aproxima do segundo modo de interpretar a reminiscência.

32 Retract. I, IV: "Item quodam loco dixi quod disciplinis liberalibus eruditi, sine dubio in se illas oblivione obrutas eruunt discendo et quodammodo refodiunt. Sed hoc quoque improbo. Credibilius est enim propterea vera respondere de quibusdam disciplinis etiam imperitos earum, quando bene interrogantur, quia praesens est eis, quantum id capere possunt, lumen rationis aeternae, ubi haec immutabilia vera conspiciunt, non quia ea noverant aliquando et obliti sunt, quod Platoni vel talibus visum est. Contra quorum 
opinionem, quanta pro suscepto opere dabatur occasio, in libro duodecimo De Trinitate disserui".

33 Inatismo no sentido de que, em todo conhecimento verdadeiro, "reencontra-se um elemento cuja origem não está nem nas coisas nem em nós mesmos..." (BROWN, 2005, p.158).

$34 \mathrm{O}$ antes aqui não se refere à temporalidade, pois a contemplação das verdades é justamente uma das provas para a atemporalidade da alma (ver: Fedon 73c).

35 De Trinitate XII, VII, 12; XII, XIV, 21b-22.

36 Ver: Conf. X, XI-XII.

37 Indo além, diríamos que o conteúdo dessa impressão na alma não são conceitos como se poderia imaginar, mas sim regras de julgamento dos demais conhecimentos, de sua adequação ao princípio da verdade. Assim, portanto, defendemos que a iluminação propõe regras (regulacionismo), tese também defendida por Gilson; outras possibilidades interpretativas são o ontologismo, tese defendida por Hessen, o abstracionismo, tese defendida por Tomás de Aquino, e o exemplarismo, tese defendida por São Boaventura. In: CAYRE, 1947, p.227-241.

38 Em De anima et eius origine, I, 4, 4, Agostinho afirma que a alma humana não é Deus nem uma parte de Deus, mas que ela foi criada do nada pela vontade divina. Entretanto, Agostinho não chega a tratar do momento de sua origem e sobre sua união com o corpo (De anima et eius orig. I, XIII, 16; IV, 11, 15-16). Em outras obras, Agostinho também não deixa claro sua posição diante dessa questão, limitando-se a demonstrar as possibilidades existentes, sem dar adesão a alguma delas (De lib. arb. III, 20, 56; De Gen. ad litt. X, 14-16; Epist. 166, IV, 8). São nos seus escritos exegéticos, entretanto, que a extensão e a dificuldade da questão ficam expostas. Brown (2005, p.451) mostra como a polêmica de Agostinho com Vincentius Victor evidencia sua indecisão quanto ao tema, com ele mesmo admitindo não ter uma posição definida (Ep. 167, I, 2). Para uma síntese da discussão, ver: De Gen. ad. litt. VII, 5- 9; 24; 27-28.

39 Retract. I, VIII, 2: "In quo libro illud quod dixi: Omnes artes animam secum attulisse mihi videri, nec aliud quidquam esse id quod dicitur discere quam reminisci ac recordari, non sic accipiendum est, quasi ex hoc approbetur animam vel hic in alio corpore vel alibi sive in corpore sive extra corpus aliquando vixisse, et ea quae interrogata respondet, cum hic non didicerit, in alia vita ante didicisse. Fieri enim potest, sicut iam in hoc opere supra diximus, ut hoc ideo possit, quia natura intellegibilis est et connectitur non solum intellegibilibus, verum etiam immutabilibus rebus, eo ordine facta, ut cum se ad eas res movet quibus connexa est vel ad se ipsam, in quantum eas videt, in tantum de his vera respondeat. Nec sane omnes artes eo modo secum attulit ac secum habet; nam de artibus quae ad sensus corporis pertinent, sicut multa medicinae, sicut astrologiae omnia, nisi quod hic didicerit, non potest dicere. Ea vero quae sola intellegentia capit propter id quod dixi, cum vel a se ipsa vel ab alio fuerit bene interrogata, et recordata respondet."

40 GILSON, 2006, p.149.

41 Soliloq. II, XX, 34.

42 Cf. CILLERUELO, 1963, p.291.

43 GILSON, 2006, p.208-209. Essa lembrança da verdade é manifesta nos homens através do desejo universal de felicidade. Esse axioma é utilizado, por exemplo, em C.Acad. I, 2, 5; De beata vita V, 2, 10; De lib. arb. I, 14, 30; De mag. XIV, 46; e explicitamente atribuído a Cícero em De trin. XIII, 4, 7.

44 Um trabalho interessante seria o de mostrar se e como a doutrina da iluminação de Agostinho se aproxima de uma interpretação que é feita da reminiscência platônica, por autores como Dixsaut e Scott, por exemplo (DIXSAUT, M. 2017, p.92-98; SCOTT, D. 1987, p.346-366 (salvaguardadas suas diferenças)). Isso porque essa interpretação afasta-se da ideia de preexistência da alma para focar-se na ideia de participação, de familiaridade ontológica da alma e das verdades que ela contempla. Assim, a experiência da anamnese descobre na alma a sua capacidade de conhecer aquilo que é de sua natureza, uma capacidade que além de epistemológica, é de seu pertencimento do mundo inteligível. Já Agostinho, na iluminação, destaca a capacidade própria da alma de receber a luz divina, que é também uma capacidade de natureza, pois a alma foi criada de tal modo que é capaz de acessar as verdades eternas. 